\title{
Agostinho, neto do canto oprimido: entre a política poética e o pesadelo da história
}

\author{
Agostinho, downtrodden song's grandson: between poetic \\ politics and history nightmare
}

Vanessa Ribeiro Teixeira

Unigranrio

vanessarteixeira@gmail.com

RESUMO: O regime de opressão política, social e cultural condiciona a desenvoltura literária característica das grandes temáticas desenvolvidas nos poemas de António Agostinho Neto. Nascido numa Angola mantida sob jugo português - juntamente com Moçambique, Guiné-Bissau, Cabo-Verde e São Tomé e Príncipe - desde o século XV, ainda que mais proficuamente a partir do século XIX, o poeta-guerrilheiro inaugura as suas andanças pela arte literária sob o crivo de uma tensão peculiar aos escritores da África colonial: como articular um discurso de resistência e reação contra um modelo opressor a partir da estrutura linguística do próprio opressor, isto é, inegavelmente imposta? Entre a angolanidade e a convocação para a ação guerrilheira, a voz do poeta Agostinho Neto busca libertar a sua própria história e a sua realização poética dos grilhões da "verdade" oficial europeia.

Palavras-chave: Poesia. Angola. História. Colonialismo. Agostinho Neto.

\begin{abstract}
The political, social and cultural oppression regime conditions the literary aplomb characteristic of the major themes developed in the poems of Agostinho Neto. Born in Angola kept under Portuguese yoke - along with Mozambique, Guinea-Bissau, Cape Verde and Sao Tome and Principe - since the fifteenth century, though more usefully from the nineteenth century, the poet-guerrilla inaugurates its wanderings through art literary under the sieve of a peculiar tension to the writers of colonial Africa: how articulate a discourse of resistance and reaction against an oppressive model from the language of the oppressor own structure, that is undeniably imposed? Between Angolanity and the call for guerrilla action, the voice of the poet Agostinho Neto search unleash their own history and his poetic achievement from the shackles of "true" European official.
\end{abstract}

Revista Texto Poético | ISSN: 1808-5385 | Vol. 18 (10 sem-2015) - p. 274 
Keywords: Poetry. Angola. History. Colonialism. Agostinho Neto.

\section{Introdução}

Em certa altura do seu texto intitulado "A desmemoria / 4", o historiador e pensador uruguaio Eduardo Galeano relembra um provérbio africano que resume e justifica os caminhos arbitrários assumidos pela história oficial dos vencedores: "Até que os leões tenham seus próprios historiadores, as histórias das caçadas continuarão glorificando o caçador" (2000, p. 116). Não é só a realidade africana que deixa entrever esses melindres pouco democráticos de histórias erguidas sobre as ruínas de diversos povos, tradições e memórias. Os desastres causados pela opressão seja ela sociopolítica, cultural ou religiosa - são universais, e, justamente por isso, tornam-se fundamentais no sentido de proporcionar a aproximação e o diálogo entre vozes e épocas históricas tão distintas, tal qual o grito do negro africano colonizado e explorado em sua própria terra, a luta pela libertação escrava no Brasil, as palavras de ordem que estouraram revoluções da causa operária na Europa e as manifestações pela conquista da liberdade política e social quando das trevas ditatoriais na América Latina.

A memória arguta e as palavras sensíveis do mestre Galeano abrem as cortinas para o canto, a um só tempo dolente e feroz, de um poeta-guerrilheiro esmerado não só em fazer ouvir o balbucio saído das cordas enrouquecidas do povo angolano, estrangulado por um regime cruel de colonização e exploração humana, como também em entoar o seu grito de revolta, ou de esperança, como uma primeira voz - grande tenor da luta pela independência política de seu país - para irmanar a causa dos homens negros oprimidos em todas as partes da grande África e do resto do mundo.

Revista Texto Poético | ISSN: 1808-5385 | Vol. 18 (10 sem-2015) - p. 275 
António Agostinho Neto, nascido em 1922, na região de Kaxicane, Angola, homem polivalente, encaminhou a sua carreira política e social atuando como médico, poeta, guerrilheiro e celebrado primeiro presidente da República Popular de Angola. Na observação de seus poemas, reunidos no livro Sagrada Esperança, publicado pela primeira vez em $1968^{30}$, perceberemos as palavras de força e resistência que direcionarão o seu percurso político. Vale lembrar que Agostinho Neto praticamente abandonou a poesia quando do início efetivo da luta armada pela libertação de Angola, liderando um dos movimentos revoltosos, o MPLA (Movimento Pela Libertação de Angola). Os seus cânticos de louvor à identidade do povo e da terra angolana aliam-se aos gritos de revolta, gravados pela tinta literária, contra o regime ditatorial opressor - bastante acirrado durante a governança de um outro António, aquele de Oliveira Salazar, primeiro ministro "vitalício" de Portugal -, evocando a junção do eu, do tu e do ele, e, consequentemente, o valor plural do "nós" como a base para um bloco de resistência e conquistas.

Entre a angolanidade e a convocação para a ação guerrilheira, a voz do poeta Agostinho Neto busca libertar a sua própria história e a sua realização poética dos grilhões da "verdade" oficial europeia.

\section{Um intelectual cindido: entre a defesa da terra e a realização poética na língua do dominador}

Entre os literatos da geração de Agostinho, a questão emblemática "em que língua escrever?" torna-se crucial, embora

${ }^{30}$ A referida edição é uma publicação bilíngue português-servo-croata. Nesse trabalho, utilizaremos a publicação da editora Ática, de 1985.

Revista Texto Poético | ISSN: 1808-5385 | Vol. 18 (10 sem-2015) - p. 276 
inteligentemente contornável. Iniciados sob os postulados de um movimento continental e pan-africanista, a Negritude e, mais regionalmente, pela afirmação da identidade angolana, a chamada literatura da "angolanidade" (décadas de 40 e 50), adotando, em seguida, a escrita combativa, de apelo à união do povo oprimido e à valorização do pronome nós, plural e solidário (finais da década de 50 até as independências, na década de 70 ), os poetas-cantores do ideal libertário africano e reveladores de vozes soterradas há séculos, entre eles Agostinho Neto, esmeraram-se em insuflar a língua portuguesa, vernáculo imposto pelo colonizador, com ambientes, colorações, incorporações e recriações típicas da cultura endógena angolana. Através da admissão de termos oriundos das línguas locais, sobretudo o quimbundo, ou da tematização de cenas, costumes e realidades diversas, próprias do tempo vivido pelo povo de Angola - que tanto podem revelar as singularidades da expressão cultural ainda preservada pelo povo, como podem ilustrar as constantes denúncias contra a exploração sofrida pelo mesmo -, a escrita literária dessa privilegiada intelectualidade, desenvolvida durante o último século do período colonial, surge como uma proposta de contradiscurso libertário, de "contraveneno" extraído do mesmo veneno, uma espécie de antídoto poético.

Além de propor a reinvenção do rígido "manual" literário da época, a geração da angolanidade, liderada por Neto, acompanhado por António Jacinto, Viriato da Cruz, entre outros, esmerou-se, também, em discutir possibilidades para se construir uma estrutura nacional independente. Nesse sentido, detectar ou assumir a irrevogável fragmentação ou multiplicidade da identidade angolana significava enfraquecer uma inteireza imaginada, desejada e necessária para a conquista de legitimidade e credibilidade política.

Revista Texto Poético | ISSN: 1808-5385 | Vol. 18 (1o sem-2015) - p. 277 
Angola e angolanos ansiavam por uma identidade nacional e isto implicava lutar contra uma face coextensiva àquela do já declinado Império Português. O experimentado "sonho de liberdade" não consegue ser sustentado independentemente de uma completa inovação dos parâmetros sociais da época, a criação de uma identidade nacional. O caso angolano, assim como a realidade da África colonial, de uma maneira geral, comprova a efemeridade da ideia de nação, algo que Ernest Renan, no século XIX, já identificava como um processo de construção contínua e inacabada e que Benedict Anderson, cerca de cem anos depois, classificou como "imaginada". Algumas definições de Anderson parecem dialogar diretamente com o caso africano, apesar de sua concepção de nação ser absolutamente universal:

A nação é imaginada como limitada, porque até mesmo a maior delas, que abarca talvez um bilhão de seres humanos, possui fronteiras finitas, ainda que elásticas, para além das quais encontram-se outras nações. Nenhuma nação se imagina coextensiva com a humanidade. (...)

É imaginada como soberana, porque o conceito nasceu numa época em que o Iluminismo e a Revolução estavam destruindo a legitimidade do reino dinástico hierárquico, divinamente instituido. (...) é imaginada como comunidade porque (...) a nação é sempre concebida como um companheirismo profundo e horizontal. Em última análise, essa fraternidade é que torna possivel, no correr dos últimos dois séculos, que tanto milhões de pessoas, não só matem, mas morram voluntariamente por imaginações tão limitadas. (1989, p. 15-16)

Assim como se utilizaram da língua do outro, do opressor, para identificar e recriar o seu próprio universo, os angolanos, em busca do seu lugar de afirmação no mundo, utilizam-se de modelos 
políticos e sociais importados. A poesia de António Agostinho Neto, por vezes, reflete um certo incômodo para com essas experiências "impróprias". A mesma ansiada fraternidade, que garantiria a alteridade de uma nação no contexto mundial, acaba por camuflar as fronteiras identitárias que foram riscadas dos mapas oficiais.

O arcabouço poético de Agostinho Neto reúne as experiências negativas vividas pelo homem angolano durante o vigorar da ditadura colonial, a valorização dos atributos da terra e dos nichos culturais de Angola, além de refletir, por vezes, o retrato confuso de um intelectual privilegiado, diante da desgraça social aplicada à maioria da população, que se vê obrigado a assumir a condição de sujeito descentrado e arrancado de sua cultura primordial, posicionando-se na faixa abstrata do "não-lugar", do "talvez". É justamente esse traço da sua poética que inaugura um conflito particular entre elementos apenas supostamente complementares; elementos esses tornados opostos em consequência da consciência angustiada do sujeito: a memória pessoal versus a memória herdada; a história vivida versus a história cantada.

Reconhecendo-se a si mesmo como um ser híbrido, isto é, um indivíduo consciente da sua experiência atravessada por culturas distintas, mas, ainda que perversamente, interpenetráveis, a angústia traçada em alguns momentos poéticos da produção de Neto pode ser reavaliada a partir de determinados pressupostos bastante em voga às portas do século XXI, décadas após a morte do líder angolano. Em O local da Cultura, Homi K. Bhabha pensa o hibridismo cultural:

(...) O hibridismo é o signo da produtividade do poder colonial, suas forças e fixações deslizantes; é o nome da reversão estratégica do processo de dominação pela recusa

Revista Texto Poético | ISSN: 1808-5385 | Vol. 18 (1o sem-2015) - p. 279 
(ou seja, a produção de identidades discriminatórias que asseguram a identidade "pura" e original da autoridade). O hibridismo é a reavaliação do pressuposto da identidade colonial pela repetição de efeitos de identidade discriminatórios. Ele expõe a deformação e o deslocamento inerentes a todos os espaços de discriminação e dominação. Ele desestabiliza as demandas miméticas ou narcísicas do poder colonial, mas confere novas implicações a suas identificações em estratégias de subversão que fazem o olhar do discriminado voltar-se para o olho do poder. (...)

Se os efeitos discriminatórios permitem às autoridades vigiá-los, sua diferença que prolifera escapa àquele olho, escapa àquela vigilância. (1998, p. 157)

Criando poesia a partir da língua do colonizador, o escritor angolano depara-se com a instigante tarefa de denunciar os traços negativos da realidade do seu povo, vitimado pelo regime opressor, assumindo que respira, estranhamente, algumas "impurezas" dos ares desse regime. Além disso, percebemos, em alguns poemas, como "À reconquista", "Na pele do tambor" ou "O verde das palmeiras da minha mocidade", o sentimento de deslocamento identitário, o que não o impede de assumir sua angolanidade, defendendo a causa libertária, ciente da sua terra, do seu direito à terra e do valor de sua gente.

Retratando as impressões e expressões quotidianas de uma África que está para além (ou aquém) dos discursos dos movimentos partidários, o sujeito poético de "À reconquista" procura arrancar as suas vestes de homem "moldado" pelo sistema em busca de uma verdade mais voltada para a tradição e para a realidade cultural de seu povo:

(...)

Vem comigo África de calças de fantasia desçamos à rua

Revista Texto Poético | ISSN: 1808-5385 | Vol. 18 (1o sem-2015) - p. 280 
e dancemos a dança fatigante dos homens o batuque simples das lavadeiras ouçamos o tam-tam angustioso enquanto os corvos vigiam os vivos esperando que se tornem cadáveres

Vem comigo África dos palcos ocidentais descobrir o mundo real onde milhões se irmanam na mesma miséria atrás das fachadas de democracia de cristianismo de igualdade

Vem comigo África dos gabinetes de estudo

e reentremos na casinha de latas esquecida no musseque da Boavista

até onde já nos empurraram

ao nos quebrarem as casas de meia água do Cayatte e à volta do fogo consolador das nossas aspirações mais justas

examinemos a injustiça inoculada no sistema vivo em que giramos.

Vem comigo África de colchões de molas

regressemos à nossa África

onde temos um pedaço da nossa carne calcado sob as botas dos magalas

onde caíram gratuitamente as gotas do suor do nosso rosto a nossa África

Vem comigo África do jitterbug até a terra até o homem até o fundo de nós ver quanto de ti e de mim faltou quanto da África esqueceu e morreu na nossa pele mal coberta sob o fato emprestado pelo mais miserável dos ex-fidalgos. (...)

Ninguém nos fará calar

Ninguém nos poderá impedir 
O sorriso dos nossos lábios não é agradecimento pela morte

Com que nos matam.

Vamos com toda a Humanidade

conquistar o nosso mundo e a nossa Paz. (1985, p. 58-59)

É clara a intenção do sujeito poético, ávido de um utópico retorno às origens, no que se refere à tarefa de despir a África, conhecida como a terra de seus ancestrais, das imposições culturais desenhadas pelos ideais europeus de progresso ou modernização. Tais pressupostos, inflamados pelas ditaduras do racionalismo, do cientificismo e do positivismo europeu, contribuem para a legitimação dos regimes coloniais e opressores nas terras consideradas "primitivas" e "atrasadas", como a africana. A configuração de uma política colonial, que pressupõe a superioridade da cultura do opressor em relação à do oprimido, resulta na configuração de elementos sociais de fronteira, embora essencialmente opostos.

Por um lado, ergue-se a figura do sujeito "híbrido", como já foi destacado nas palavras de Homi Bhabha, como aquele indivíduo formado a partir da interpenetração e, posteriormente, da profícua reavaliação das verdades impetradas pelos postulados do sistema colonial. A partir de uma convivência forçada entre culturas, o sujeito híbrido, aproveitando o acesso aos elementos-base formadores de ambas, decide-se por articular um discurso de defesa da sua cultura / terra de origem, procurando minar, no nascedouro linguístico do sistema oficial, o próprio sistema opressor.

A irônica apropriação de elementos que marcam o sufocamento cultural, idealizado pelo colonizador europeu ("calças de fantasia", 
"palcos ocidentais", "gabinetes de estudo", "colchões de mola", "jitterburg"), vai ao encontro da crítica a uma cultura imposta e da valorização de uma identidade singular, definida na tradição e no arcabouço sociocultural endógeno.

Além disso, tendo sido um poema datado do início da década de 50, o discurso de louvação de uma terra africana de reencontro e de retorno a valores próprios, articulados internamente, acaba por irmanar-se às propostas nascentes de posicionamento combativo e de chamamento à ordem, visando o insuflar dos espíritos para a luta libertária: "Ninguém nos fará calar / Ninguém nos poderá impedir / O sorriso dos nossos lábios não é agradecimento pela morte / com que nos matam. // Vamos com toda a Humanidade / conquistar o nosso mundo e a nossa Paz.".

Caminhando ao encontro da epígrafe tomada a Eduardo Galeano para a abertura deste trabalho, as palavras do sujeito poético de "À reconquista" reatualizam a noção de que, partindo da proposta de recuperação dos valores endógenos e sabendo desfrutar dos conhecimentos sobre a cultura do dominador, a fim de dessacralizálo e torná-lo vulnerável, criam-se novas esperanças com o intuito de revitalizar vozes desacordadas e embriagadas por séculos de opressão. Além disso, clama-se, à força da pluralidade, do grito na $1^{a}$ pessoa do plural, a junção necessária para o enfraquecimento dos tentáculos do monstro opressor, vindo de além-mar.

Por outro lado, na contramão da postura de resistência e consciência combativa do sujeito híbrido, surge o retrato trágico do indivíduo "assimilado". Em síntese, após deparar-se com a vivência deplorável das comunidades "vencidas", busca a todo custo distanciar-se dessa realidade, da qual também é vítima, procurando revestir-se inteiramente dos padrões que sustentam a cultura 
dominadora, ampliando a sua condição agônica de "não-lugar", segundo a qual nunca poderá escapar totalmente da sua singularidade oprimida, assim como nunca participará, com inteireza, dos postulados identitários que sustentam a soberania do opressor. Em outras palavras, o negro assimilado deseja conquistar os poderes e o discurso do branco colonizador, não com o intuito de pervertê-los, mas incorrendo na sua reafirmação. Constituem-se, então, como elementos opressores de segunda ordem. Não configurando uma temática central para este trabalho, visto que representa um tipo de comportamento "ambivalente" distinto daquele assumido pelo poeta Agostinho Neto, o processo de assimilação das sociedades oprimidas e, mais especificamente, do homem africano, pode ser analisado melhor em textos salutares, como Peles Negras, Máscaras Brancas, de Franz Fanon.

Retomando a consciência intrigante do sujeito híbrido, reconhecedor da sua identidade inegavelmente múltipla, mas profundamente crítico quanto à forma com que essa diversidade se instaurou, denunciando e desmitificando os crimes arrolados pelo regime colonial, o eu poético de "Na pele do tambor" deixa ecoar o deslumbre de ver-se seduzido por uma representatividade cultural bastante peculiar e próxima, embora reveladora do seu distanciamento factual daquilo que se concebe por expressividade cultural endógena. Não é à toa que a busca angustiante pelo reflexo desse sujeito poético se resume a um verso interrogativo, fundamental para todo um processo de autognose e releitura identitária sócio-histórica: “Onde estou eu? quem sou eu?" (NETO, 1985, p. 64). A partir dessas indagações, outras são evocadas e tornase imprescindível para o ser deslocado, que busca conhecer-se para defender e exibir essa face diante do mundo agressor, recorrer à 
coletividade e ao sentimento de irmandade para com os filhos de uma mesma terra oprimida, a fim de reconstruir-se e proclamar a liberdade:

\author{
(...) \\ Vibro \\ em áfricas humanas de sons festivos e confusos \\ (que línguas pronunciais em mim irmãos \\ que não vos entendo neste ritmo?) \\ Nunca me pensei tão pervertido \\ ó impureza criminosa dos séculos coloniais \\ (que história é essa da lebre e da tartaruga \\ que contas neste novo ritmo de fogueira \\ à noite \\ minha avozinha de pele negra de África?) \\ (...)
}

As mãos entrelaçadas sobre mim

em gozo de vida em gargalhadas em alegrias

de lagos libertados por amplos verdes

para os mares

dão-me o tom da minha áfrica

dos povos negros do continente que nasce

fora dos abismos escurecidos da negação

ao lado de ritmos de dedos congestionados

sobre a pele envelhecida do tambor

dentro do qual vivo e vibro e clamo:

AVANTE!

(1985, p. 114-116)

O reconhecimento da sua condição de indivíduo vitimado pelo processo de alteração cultural e, consequentemente, identitária, que o aproxima salutarmente de alguns módulos estruturantes da cultura colonizadora - como língua, comportamento, profissão, trajes e

Revista Texto Poético | ISSN: 1808-5385 | Vol. 18 (10 sem-2015) - p. 285 
costumes -, acaba por se tornar algo positivo quando do alumbramento e curiosidade do sujeito diante daquilo que se pode conceber também como cultura sua. Não perdendo de vista a sua verdade enquanto sujeito híbrido, o eu-poético, salvo das garras da completa "aculturação", vê na emergência da coletividade e da solidariedade ("as mãos entrelaçadas”) a saída para uma espécie de harmonização das realidades dos diversos filhos da mãe África, polifônica e autêntica.

Esse ideal de coletividade permeara, também, a problematização central do poema "Pausa", datado de 1951. Através da exposição poética dos limites entre as vergonhas e as virtudes do ser humano, o eu-lírico deixa grafada, uma vez mais, a emergência do seu sentimento de "persona" cindida, tanto íntima quanto culturalmente:

Há esta angústia de ser humano quando os répteis se entrincheiram no lodaçal e os vermes se preparam para devorar uma linda criança em indecorosa orgia de crueldade

E há esta alegria de ser humano quando a manhã avança suave e forte sobre a embriaguez sonora do cântico da terra apavorando vermes e répteis

E entre a angústia e a alegria um trilho imenso do Niger ao Cabo onde marimbas e braços tambores e braços vozes e braços harmonizam o cântico inaugural da Nova África (NETO, 1985, p. 94)

No entanto, é na síntese dessa verdade múltipla, insuflada de elementos positivos e negativos, que se pretende buscar as 
esperanças para a renovação da situação vigente, caracterizada pelos agrilhoar dos braços e pelo amordaçar das vozes. Ao mesmo tempo em que se propõe a valorização da força, do som e das potencialidades vocais do coral africano, por séculos estrangulado, os braços que evocam o sentimento solidário convocam, também, a releitura e a rearticulação da história, que insiste em ocultar verdades outras e sufocar as vozes vencidas.

\section{Reler a história e recriar verdades com "os olhos secos"}

A poesia é a Memória feita imagem e esta convertida em voz. A outra voz não é a voz do além-túmulo: é a do homem que está dormindo no fundo de cada homem. ("A outra voz" - Octavio Paz)

A história dos vencidos, grafada e encadernada, surge dessa necessidade dos povos oprimidos em assegurar a sua soberania sobre a cultura e território próprios. Redescobrindo, sob as ruínas resultantes da incorporação forçada de uma história unilateral e gradiloquente - estruturada sobre as bases discriminatórias dos impérios europeus -, as suas fontes de constituição memorialista e os ícones de fundação da sua identidade, a perspectiva de evocação de uma "nova história" africana, segundo a qual dar-se-á voz à condição do vencido, impera junto ao sentimento de esperança na criação de uma nova pátria.

Em História e Memória, Jacques Le Goff, apoiado nas prerrogativas de Georges Duby e Lardreau, entre outros, afirma que “todo documento é um monumento ou um texto, e nunca é 'puro', isto é, puramente objetivo" (1996, p. 30). Diante dessa concepção 
"moderna" sobre os descaminhos da produção histórica, e aproximando-a da ideologia renovadora do discurso poético de Agostinho Neto, vale atentar, ainda, para uma importante colocação de Duby, segundo a qual "a história é acima de tudo uma arte, uma arte essencialmente literária. A história só existe pelo discurso. Para que seja boa, é preciso que o discurso seja bom" (DUBY e LARDREAU apud LE GOFF, 1996, p. 38). Apesar de provocar alguns conflitos relativos à compreensão dos limites entre estudos históricos e produções literárias, esse conceito serve, sobremaneira, para revitalizar as prerrogativas de que a arte, de uma maneira geral, incorre, através de seu debruçar crítico sobre a realidade, na leitura reveladora de episódios fulcrais para o caminhar histórico de determinada sociedade, retirando de baixo de luxuosos tapetes a poeira escondida, testemunha e denunciadora de verdades outras, além de resguardar as potencialidades visionárias, antecipando crises ontológicas, sociológicas e políticas.

Para além disso, as palavras de Duby deixam clara a ideia de que o vigorar de determinado discurso histórico depende da supremacia contextual e política de determinado grupo. Por fim, não existe história de colonizador que glorifique as aventuras de um colonizado. Lembram-se do provérbio africano exposto na introdução deste trabalho? Ilustrando a necessidade do líder guerrilheiro africano, ávido de liberdade política e discursiva como meio de garantir a soberania identitária de sua própria terra, poemas como "Confiança", "Não me peças sorrisos" e "Consciencialização" esmeram-se em transmitir, por veias poéticas, ora o sentimento consciente de anulação da voz oprimida diante da confecção do relato e da caminhada histórica oficial - “(...) Não me exijas glórias / que sou eu o soldado desconhecido / da Humanidade // As honras 
cabem aos generais // (...) // Uma cabeça sem louros / porque não me encontro por ora / no catálogo das glórias humanas" (NETO, 1985, p. 44) -, ora a necessidade crescente de tomada da palavra e delineamento dos arabescos que sustentam a leitura histórica.

Em "Confiança", por exemplo, junto à experiência dramática da exploração humana e da súbita mudança de expectativas, costumes, memórias e histórias, o eu poético sublinha a noção de direito que está no nascedouro das revoluções libertárias e prepara tanto o combatente quanto o intelectual para a tomada de consciência sobre o seu papel e sua importância para a constituição da sociedade moderna e do poder discursivo, com o qual se poderá reerguer a comunidade oprimida:

O oceano separou-me de mim

enquanto me fui esquecendo nos séculos

e eis-me presente

reunindo em mim o espaço

condensando o tempo

Na minha história

existe o paradoxo do homem disperso

Enquanto o sorriso brilhava

no canto de dor

e as mãos construíam mundos maravilhosos

John foi linchado

o irmão chicoteado nas costas nuas

a mulher amordaçada

e o filho continuou ignorante

E do drama intenso

duma vida imensa e útil

resultou a certeza

Revista Texto Poético | ISSN: 1808-5385 | Vol. 18 (1o sem-2015) - p. 289 
As minhas mãos colocaram pedras

nos alicerces do mundo

mereço o meu pedaço de pão

(NETO, 1985, p. 41)

A conscientização da sua importância para a trajetória histórica de toda a humanidade configura-se como um primeiro passo para a relativização e, até mesmo, a anulação de discursos oficiais discriminatórios e laudatórios de uma verdade única: a do sangue colonial (ou "neocolonial") derramado em nome da ânsia constante pela afirmação do poder.

$\mathrm{Na}$ busca pelos direitos do homem angolano - tanto quanto do homem africano ou do indivíduo oprimido numa perspectiva universal -, a luta de intelectuais que visam recriar a história a partir de um tecido produzido por sua própria cultura, sua terra e seu povo, assumindo a produção dos fios, a coloração das fibras e, até mesmo, a criação do bicho$d a$-seda, é uma luta que exige a rearticulação de discursos desafiadores da "verdade única"31. Continua a parecer irônica a franqueza e naturalidade com que um famoso ministro dos Negócios Estrangeiros de Portugal, o Sr. Franco Nogueira, em 1967, reafirma a "soberania" da cultura portuguesa e o seu caráter indispensável para a formação dos sentimentos de humanidade e fraternidade na África colonial:

(...) nós antes de todos os outros levamos à África a idéia de direitos humanos e de igualdade racial. Só nós praticamos o "multirracialismo", a expressão mais perfeita da fraternidade entre os povos. Ninguém no mundo contesta a validade deste princípio, mas hesita-se um pouco em admitir que é uma invenção portuguesa, e reconhecê-lo faria crescer nossa autoridade no mundo. (FERRO, 1996, p. 169)

${ }^{31}$ A concordância com as ideias de Chimamanda Adichie parece clara.

Revista Texto Poético | ISSN: 1808-5385 | Vol. 18 (10 sem-2015) - p. 290 
Só a observação da própria realidade oprimida dos povos mantidos sob o jugo lusitano poderá contra-argumentar uma assertiva tão séria e segura, por mais absurda que pareça. Percorrendo o caminho inverso desses discursos oficiais e contraditórios, quiçá arbitrários, da política colonial, evoco as palavras do poema "Consciencialização", com as quais o sujeito poético proclama a reescritura da história social de sua comunidade a partir da luta pela valorização da cultura endógena, embalada pela Mãe África, junto à iniciativa de combate pela libertação política do povo oprimido. Africanismo, angolanidade e poética guerrilheira irmanam-se, novamente, na realização literária de Agostinho Neto:

\section{Medo no ar!}

Em cada esquina

sentinelas vigilantes incendeiam olhares

em cada casa

se substituem apressadamente os fechos velhos

das portas

e em cada consciência

fervilha o temor de se ouvir a si mesma

A História está a ser contada

de novo

Medo no ar!

Acontece que eu

homem humilde

ainda mais humilde na pele negra

me regresso África

para mim

com os olhos secos.

[Agosto de 1951]

(1985, p. 49) 
O clima de tensão e vigília resulta da ameaçadora iniciativa de se tomarem nas próprias mãos, mãos calejadas de homens (e mulheres) forçados a calar por tanto tempo, o rumo da atividade histórica, além da orquestração de seus escritos e de suas verdades discursivas; a história está a ser reescrita e recontada. O homem do povo, o soldado esquecido, o colonizado oprimido insuflam o peito e reanimam os braços para retomarem para si as venturas e desventuras do próprio destino.

A sociedade estabelecida pelo regime colonial padece com o medo provocado pela expectativa de libertação do grito sufocado dos vencidos. Quem saberá da sua potência e seu poder letal quando guardados por grilhões e chibatas durante séculos? Quem saberá qual será a sua nova posição diante da tão esperada volta (ou revolta) da "roda do mundo"?

O comando e participação na luta armada pela libertação de Angola interrompe as realizações poéticas de Agostinho Neto, o futuro presidente da nação utópica. Entre a ação e o discurso, ganhou a História. Terá perdido a Poesia?

\section{Conclusões esperançosas}

Observando a trilha poética percorrida por Agostinho Neto, torna-se bastante complicado distinguir as "fases" de exploração temática (a fase da "angolanidade", a fase da "poesia guerrilheira", por exemplo) com exatidão. $\mathrm{Na}$ verdade, são ideias, ideais e realizações potencialmente entrecruzadas, mescladas, embora seja possível, em alguns poemas, detectar "um tom a mais", no sentido de diferenciar uma problemática de outra.

Revista Texto Poético | ISSN: 1808-5385 | Vol. 18 (10 sem-2015) - p. 292 
As investidas poéticas voltadas para a reflexão do sujeito híbrido, herdeiro de uma realidade multicultural, tornam-se momentos fulcrais de discussão sobre a posição deste indivíduo no contexto da sociedade colonial, fazendo-o reaver e recriar como suas as verdades resguardadas pela cultura endógena, do colonizado. As agruras do povo oprimido, mesmo quando não são sentidas na pele do intelectual, junto às suas expressões socioculturais singulares, erguem a estrutura que sustenta o discurso de resistência deste ser ambivalente.

Por outro lado, a tomada de consciência sobre a importância da participação histórica de seu povo leva o sujeito poético da obra de Agostinho Neto a proclamar o direito de subverter os pilares dessa história "oficialmente" concebida, partindo da segurança de saberse sujeito/agente das trilhas percorridas pela sociedade mundial e não apenas objeto manipulado pelas correntes da opressão.

\section{Referências}

ANDERSON, B. Nação e consciência nacional. Trad. Lólio Lourenço de Oliveira. São Paulo: Ática, 1989.

BHABHA, H. K. O local da cultura. Belo Horizonte: Ed. UFMG, 1998.

FERRO, M. História das Colonizações: Das conquistas às independências, séculos XIII a XX. Trad. Rosa Freire d'Aguiar. São Paulo: Companhia das Letras, 1996.

GALEANO, E. O livro dos abraços. 7. ed. Trad. Eric Nepomuceno. Porto Alegre: L\&PM, 2000.

LE GOFF, J. História e Memória. Campinas: Ed. UNICAMP, 1990.

NETO, A. A. Sagrada Esperança. São Paulo: Ática, 1985. 
PAZ, O. A outra voz. Trad. Wladir Dupont. São Paulo: Siciliano, 1993.

RENAN, E. Qu'est-ce qu'une nation? / What is a nation? (Introdução).

Toronto, Ontario: Tapir Press, 1996. 